\title{
LA METÁFORA BÉLICA DURANTE LA CRISIS SANITARIA DE LA GRIPE A
}

\author{
Ricardo Morant Marco - Arancha Martín López \\ Universitat de València \\ ricardo morant en uv es \\ arantxaml en ono com
}

\section{Resumen}

Este artículo pretende demostrar que la metáfora bélica empleada por los medios de comunicación para informar sobre el virus H1N1 durante la crisis sanitaria de la gripe A fue un recurso comunicativo fundamental. Esta analogía provocó un fuerte sentimiento de miedo entre la población que condujo a muchas personas a exigir al Gobierno la adquisición de ciertos fármacos y vacunas para protegerse ante la nueva enfermedad. Para realizar esta investigación se ha partido de las informaciones publicadas en tres medios de comunicación nacionales -El País, El Mundo y ABC-durante seis meses, además de estudios académicos y otros documentos y artículos difundidos a través de medios de comunicación tradicionales e Internet.

Palabras clave: metáfora bélica, lenguaje de la guerra, lenguaje del miedo, gripe A.

Morant Marco, Ricard, y Arantxa Martín López. 2011.

La metáfora bélica durante la crisis sanitaria de la gripe A.

Círculo de Lingüística Aplicada a la Comunicación 46, 91-112.

http://www.ucm.es/info/circulo/no46/morant.pdf

http://dx.doi.org/10.5209/rev_CLAC.2011.v46.3

(C) 2011 Ricardo Morant Marco y Arancha Martín López

Círculo de Lingüística Aplicada a la Comunicación (clac)

Universidad Complutense de Madrid. ISSN 1576-4737. http://www.ucm.es/info/circulo 
Abstract: Wartime metaphors during the H1N1 flu health crisis

This article aims to illustrate how became a fundamental communicative resource for the mass media when reporting on the H1N1 virus during the swine flu health crisis. This analogy heightened public fear so much so that many individuals demanded that the government acquire certain drugs and vaccines to protect themselves from the virus. This research is based on the information which appeared in three national dailies -El País, El Mundo and ABC- over a six-month period, as well as academic publications, documents and articles available in the media and Internet.

Key words: Wartime metaphors, battle discourse, language of fear, swine flu.

Índice

Resumen 91

Índice 92

1. Introducción 92

2. El papel de los medios de comunicación 94

3. La gripe A y la metáfora de la guerra 97

4. Conclusiones 108

Bibliografía 109

Artículos periodísticos 111

1. Introducción

En este artículo se analiza la metáfora bélica utilizada por los medios de comunicación en las noticias sobre la gripe A, desde la aparición de los primeros casos, en abril de 2009, y durante un periodo de seis meses ${ }^{1}$. Para ello, se ha estudiado la

\footnotetext{
${ }^{1}$ Este artículo se ha realizado en el marco del proyecto I+D titulado "Retórica y cultura en la información periodística sobre salud” (HUM2007-65132), cofinanciado por el Ministerio de Ciencia e Innovación
} 
edición digital de El Mundo entre el 24 de abril y el 14 de octubre, además de la edición digital de El País y la edición impresa de ABC entre el 24 de abril y el 16 de octubre. La elección de estos diarios responde a que son los de mayor tirada y difusión en nuestro país y, por tanto, los de mayor impacto en la población. La recogida de noticias se realizó mediante un vaciado diario de estos periódicos teniendo en cuenta los titulares, entradillas y textos de las mismas. Las noticias de estos periódicos (64 de ABC, 76 de El Mundo y 141 de El País) se han complementado con trabajos académicos y con otros artículos escritos con posterioridad a estas fechas, publicados en medios de comunicación convencionales y también a través de Internet.

En el desarrollo de esta investigación se han seguido dos pasos: selección de la muestra y creación del corpus; y análisis sobre cómo las noticias difundidas sobre la gripe A recurrieron, en gran medida, a la guerra como metáfora.

A lo largo de las siguientes páginas se pretende demostrar que la metáfora militar usada en los medios de comunicación a la hora de informar sobre la gripe $A$ fue más que una simple metáfora, pues tuvo un enorme impacto entre la población: primero colaboró en la creación de un miedo generalizado en la sociedad y, después, influyó en su comportamiento, en la petición masiva de medicamentos para afrontar esa emergencia sanitaria.

En este sentido, se hace una referencia inicial al papel de los medios en la generación de un estado de opinión sobre los temas que tratan, puesto que, como advierte Buckingham (2005: 100), "los medios no nos ofrecen una transparente 'ventana sobre el mundo', sino más bien una versión mediada del mundo. No se limitan a presentar la realidad sino que la re-presentan”.

Tras la reflexión sobre el papel de los medios, se analiza, en el caso concreto de las noticias sobre la gripe A, la incidencia que la metaforización castrense tuvo en la creación del miedo. Este sentimiento se propagó rápidamente e hizo sentir a muchos ciudadanos la necesidad de exigir a las autoridades sanitarias la compra de determinados

(España) y los fondos FEDER, así como el proyecto "Verificación experimental de la conciencia del habla examinada mediante pruebas realizadas a hispanohablantes” (FFI 2008-05248). Nos gustaría agradecer a los dos evaluadores el trabajo que han realizado, ya que nos ha enriquecido mucho. 
fármacos para protegerse. Y es que las informaciones que les llegaban a través de la prensa tenían el aspecto de una narración bélica, que hablaba de la existencia de un temible enemigo -el virus H1N1, que provocaba la gripe A-; de su rápido avance desde su foco original, convirtiendo en potenciales víctimas a toda la población mundial; de la intervención de un ejército, integrado por las diversas autoridades sanitarias; y de las tácticas y armamento utilizados para combatir esta nueva gripe.

Durante varios meses los medios llevaron a sus primeras páginas las informaciones sobre esta enfermedad dando trato prioritario cada día a las comparecencias de las autoridades, en las que resumían cuál era la situación en un tono que recordaba mucho los partes de guerra.

2. El papel de los medios de comunicación

Durante la crisis de la gripe A se puso de manifiesto, una vez más, que el cómo se comunicó fue tan importante como el qué. Esta enfermedad se convirtió en un nuevo ejemplo de que no solo es importante lo que se dice sino que la manera de decirlo determina también la visión que los receptores se forjan sobre un acontecimiento y puede incidir en su forma de pensar y en su comportamiento.

Idoia Camacho (2009) se refiere al papel de la prensa que, mediante su interpretación de la realidad ${ }^{2}$, condiciona el pensamiento y la actitud de quienes constituyen su audiencia:

Los estudios desarrollados a partir de las aportaciones teóricas de la Agenda Settling y la teoría del Framing concluyen que la percepción que el público tiene de los asuntos sociales está

\footnotetext{
${ }^{2}$ En palabras de Cuenca (2010: 77): “En els mitjans de comunicació, la realitat no és, sinó que sovint es presenta, es 'construeix', d'una determinada manera mitjançant estratègies retòriques basades en la metàfora, la comparació o la paradoxa, entre altres mecanismes”.
} 
condicionada, en gran parte, por la contribución de los medios de comunicación. Un mayor énfasis mediático sobre un determinado tema o asunto social tiende a provocar en la opinión pública una mayor preocupación sobre este tema. Por tanto, los medios dictan implícitamente a los receptores una forma de pensar sobre ciertos asuntos al dar un enfoque determinado a las noticias, por cuanto seleccionan y enfatizan palabras, expresiones e imágenes, para conferir un punto de vista o una perspectiva concreta (Igartua, 2007: 93-94).

Hay quien va más allá y ve en la presentación de las noticias una relación perversa entre los medios de comunicación y los poderes económicos y políticos que los financian. Es el caso del periodista Miguel Jara ${ }^{3}$, que critica este modo de informar:

\begin{abstract}
Está sucediendo en los grandes temas que afectan a la salud de las personas (y a su economía y a la vida política y a la ecología). Los medios, en general, se postulan como valedores de los intereses de los poderosos. Esto es justo lo contrario de lo que ha de ser el periodismo y lo que estudiamos en las facultades de ídem. En buena medida esta relación perversa está producida porque la financiación de los medios viene precisamente de los poderes económicos y políticos que están produciendo daños medioambientales, sociales, laborales, económicos, ecológicos en la salud de la población, aquellos que deberían ser investigados y sobre los que habría que publicar.
\end{abstract}

Isaac Belmar ${ }^{4}$ ofrece otra explicación sobre el modo de informar habitual de los medios de comunicación, al afirmar que el miedo vende más que la tranquilidad: “Con el miedo se consigue atención, una de las mercancías más valiosas en la actualidad, donde apenas tenemos tiempo para hacer caso a nada”.

\footnotetext{
3 “Periodismo de cortar y pegar", 4 de agosto de 2010.

http://www.migueljara.com/2010/08/04/periodismo-de-cortar-y-pegar/ [Fecha de consulta: 4 de agosto de 2010].

4 “El sucio secreto del marketing”, 24 de abril de 2008. www.data-red.com/cgi-

bin/articulos/ver.pl?id=2010911181451
} 
En el caso de la gripe A, el modo en que informaron los medios contribuyó a generar ansiedad entre los ciudadanos. La prensa recurrió a estrategias verbales y no verbales como la publicación constante de noticias sobre el tema, su colocación en primera plana, el empleo de un tono que suscitaba alarma y el bombardeo de imágenes que hacían pensar en una guerra bacteriológica (gente protegiéndose con mascarillas y guantes de látex, científicos analizando el virus con escafandras y trajes de astronautas, ciudades fantasma, vacías, sin gente, en pleno día...).

Para Idoia Camacho (2009), la prensa española ofreció “una información demasiado alarmista y sensacionalista” y, según Lorente (2010), proyectó “una imagen desmesurada, catastrófica y espectacular de los peligros asociados a la pandemia”. Hubo quien vio en esta creación del miedo una intencionalidad dirigida a generar una reacción muy concreta: la compra masiva de vacunas y medicamentos por parte de los gobiernos y los ciudadanos para protegerse del virus terrible que se presentaba así porque era nuevo -y, por tanto, impredecible-, muy contagioso, mutante, rápido, imparable y letal.

El recurso al lenguaje castrense y a la metáfora bélica influyó, en gran medida, en la creación de un sentimiento de miedo. Fue uno de los instrumentos clave del marketing del miedo, una estrategia ${ }^{5}$ consistente, según Miguel Jara, en utilizar enfermedades leves para crear alarma social y extender la sensación de tensión y preocupación, con el propósito de que la gente busque los tratamientos que crean los mismos que generan los temores.

No hay que olvidar que la guerra genera inconscientemente miedo, puesto que se asocia a catástrofe, como se refleja en algunos refranes: "La guerra asuela la tierra”, “La guerra todo lo malo lo trae, y todo lo bueno se lo lleva”. Y, como dice Lorente (2010), el riesgo es también una llamada a la acción:

En términos modales, el riesgo se presenta como un saber que se transforma inmediatamente en un poder o deber hacer. El discurso del riesgo no es meramente descriptivo, una utopía negativa

\footnotetext{
${ }^{5}$ Véase la entrevista titulada “El marketing del miedo" (www.rebelion.org/docs/126235.pdf) realizada por Salvador López Arnal a Miguel Jara.
} 
conformada por temores y esperanzas, sino también una guía normativa, un manual práctico de acción que indica lo que se puede o se debe hacer.

Durante la crisis de la gripe A, la prensa empleó un discurso castrense para informar sobre la evolución de esta enfermedad. Era un discurso de estrellas, galones, palabras caqui y ruido de sables, que ayudó a imponer una cosmovisión de la realidad determinada, muy preocupante, que tuvo una enorme incidencia en el comportamiento de las personas.

El uso de la metáfora bélica en los medios durante la evolución la gripe A es, precisamente, el objetivo de este trabajo. A su análisis se dedican las siguientes páginas.

\section{La gripe A y la metáfora de la guerra}

La metáfora en la actualidad se sitúa, según comenta Díaz (2005: 38), no solo entre las figuras con una función ornamental, sino también “entre los recursos lingüísticos con una finalidad persuasiva y las herramientas cognitivas para conceptualizar el mundo y explicar e interpretar la realidad”. En el presente trabajo partiremos de esta última idea $^{6}$, defendida por Lakoff y Johnson (1980) en la denominada teoría de la metáfora conceptual. Estos estudiosos definen este mecanismo como una destreza cognitiva fundamental de uso cotidiano y habitual y muchas veces imperceptible, consistente en entender cosas complejas en términos de otras más simples ${ }^{7}$. De los distintos tipos de metáforas distinguidas por estos investigadores, nosotros dejaremos de lado las de imagen $^{8} \mathrm{y}$ nos centraremos en las conceptuales, las cuales, en palabras de Cuenca y

\footnotetext{
${ }^{6}$ Para una visión panorámica de la metáfora desde los inicios clásicos hasta las teorías lingüísticas más recientes véase la tesis de M. Á. Moreno (2005).

${ }^{7}$ Para una caracterización formal de la metáfora véase Cuenca (2010).

${ }^{8}$ Se trata de metáforas concretas que proyectan la estructura esquemática de una imagen sobre la de otra.
} 
Hilferty (1999: 104), “funcionan como plantillas cognitivas que proporcionan campos semánticos enteros de expresiones metafóricas”. En este tipo de metáforas básicas existe un dominio origen, que se proyecta, que presta sus conceptos al dominio meta, o sea, ciertos elementos convencionales del dominio fuente se usan para conceptualizar y razonar sobre el dominio meta. Estas metáforas se basan en una proyección metafórica que se lleva a cabo mediante un número determinado de correspondencias que enlazan el dominio origen con el dominio destino. Estas correspondencias pueden ser de dos tipos: las ontológicas (ponen de manifiesto las relaciones analógicas existentes entre las partes más relevantes de cada dominio) y las epistémicas (aspectos de conocimiento comunes a ambos dominios). Con el fin de dejar claros todos estos conceptos nos serviremos del ejemplo empleado por Cuenca y Hilferty (1999: 101-102) para ilustrar las nociones expuestas. Para estos estudiosos, LAS IDEAS SON ALIMENTOS sería una metáfora conceptual. El dominio origen sería LOS ALIMENTOS y el dominio meta, LAS IDEAS. De esta metáfora conceptual básica surgirían diversas expresiones metafóricas concretas como “¿Y eso cómo se come?” o “No me trago lo que me estáis diciendo”. En cuanto al tipo de proyecciones que se llevan a cabo entre el dominio origen y el dominio meta, tenemos, por un lado, las proyecciones ontológicas, las correspondencias existentes entre ambos dominios:
A.- Las ideas corresponden a los alimentos.
B.- La persona que come los alimentos corresponde a la persona que acepta la idea.
C.- Cocinar el alimento corresponde a concebir la idea.
D.- Digerir el alimento corresponde a comprender la idea.

Por otro lado, tendríamos las correspondencias epistémicas, los aspectos del conocimiento comunes a ambos dominios, en este caso:

Dominio origen: los alimentos sustentan el cuerpo.

Dominio destino: las ideas sustentan la mente. 
Ahora bien, las metáforas, además de para hacer más sencillas e inteligibles determinadas cuestiones, se usan como mecanismo de persuasión. Lluís Pastor (2010: 51) se refiere a esta fuerza de las metáforas, a su influencia sobre el modo de pensar (y también de sentir y de actuar) de las personas, al afirmar que “Amb les metàfores no solament estem comparant dues realitats, sinó que també estem dient al públic què és el que ha de pensar” y añade que "Per aquesta raó les metàfores són tan importants en la nostra vida diària, perquè conformen la nostra ment segons els interessos de qui les crea”. En otras palabras, “Amb les metàfores veig el món amb els ulls de qui ha proposat la metàfora” (Pastor 2008: 99). Este hecho ya lo dejó muy claro Lakoff (1992) al analizar la Guerra del Golfo, mostrando cómo el presidente de los Estados Unidos, para lograr el apoyo del público en esa intervención bélica, aplicó el esquema metafórico del CUENTO DE HADAS basado en tres elementos: un villano (Irak), una víctima (Kuwait) y un héroe (Estados Unidos y sus aliados). De esta manera, se presentaba el conflicto, no como una guerra por el petróleo, sino como el rescate de una víctima indefensa.

Entre las metáforas, la bélica es una de las de uso más frecuente en nuestra sociedad. Está presente en numerosos ámbitos y, así, se emplea, por ejemplo, para conceptualizar la discusión (Lakoff 1980), pero también para describir enfrentamientos deportivos (Jordi Salvador Duch ${ }^{9}$ ) o para hablar de conflictos lingüísticos. A estos últimos, concretamente a la guerra en la prensa escrita del catalán y el castellano en Cataluña, dedica Cuenca (2010) un artículo en el que muestra que "la principal metàfora observada en les notícies analitzades és LA SITUACIÓ DE CONTACTE DE LLENGÜES ÉS UNA GUERRA”. Teruel (1997: 263) explica con claridad a qué se debe este uso habitual de la metáfora bélica ${ }^{10}$ en la prensa:

\footnotetext{
${ }^{9}$ La tesis doctoral de este investigador defendida en la Universitat Rovira i Virgili en 2006 posee un título muy ilustrativo: Futbol, metàfora d'una guerra freda.

10 Silvia Cebrián (2002-2003) en su trabajo sobre el papel de la metáfora en el discurso ordinario se pregunta -y se contesta- sobre la presencia de este recurso en el lenguaje y lo hace en estos términos:

¿Por qué este uso de metáforas bélicas? ¿Por qué esa belicosidad en nuestra forma de actuar? Pues bien, es una realidad que la historia de la guerra va unida a la historia de las civilizaciones,
} 
El nombre tan elevat de títols que fan servir expressions de la guerra per parlar de temes que no són literalment "guerres" indueix a pensar que en la nostra cultura gran part de la realitat és concebuda en termes bèl-lics i d'enfrontament. Guanyar o perdre sembla, per tant, la gran metàfora d'aquesta societat (o de totes?).

Nosotros, a continuación trataremos la metáfora bélica pero en el campo de la enfermedad $^{11}$, concretamente en el de la gripe A. Para ello partimos del siguiente esquema:

\section{Metáfora conceptual: LA ENFERMEDAD ES UNA GUERRA}

Dominio Origen Dominio Destino

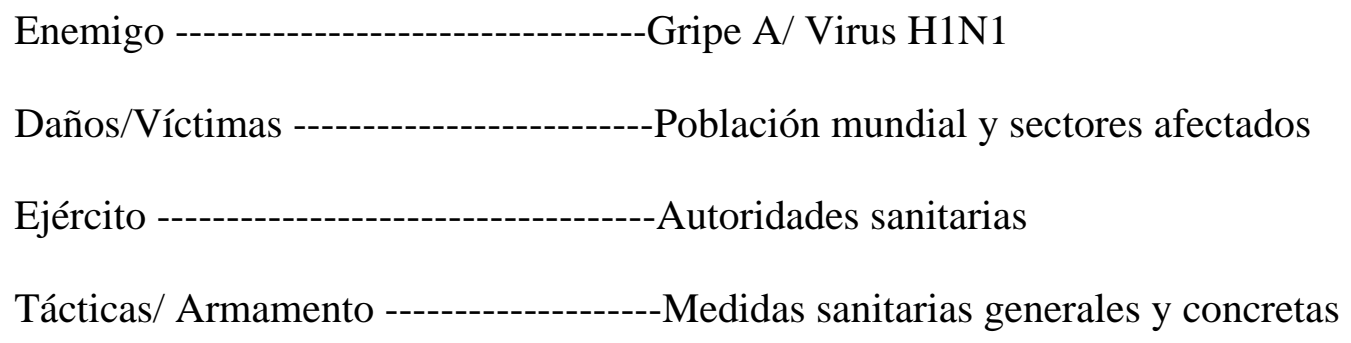

Las noticias que informaron sobre la gripe A se valieron, como acabamos de ver, de la metáfora conceptual “LA ENFERMEDAD ES UNA GUERRA”. Es decir, a partir

desde las civilizaciones mesopotámica, egipcia, romana... hasta la moderna [...]. Otra causa viene dada por el hecho de que nuestra sociedad se halla inmersa en un capitalismo salvaje que provoca la competencia entre nosotros, todo viene marcado por el ganar o perder, por ser el mejor o el peor [...] vivimos en una cultura discriminadora, machista, xenófoba, homófoba, cosa que nos lleva al aislamiento individual, al egoísmo y a una eterna lucha con el prójimo.

${ }^{11}$ Sobre la enfermedad y la metáfora se encuentran, por ejemplo, los trabajos de Sontag $(1980,1989)$. La tesis central de esta ensayista americana es que el empleo de metáforas para conceptualizar la enfermedad es un recurso perjudicial para el paciente. Mantiene que "la enfermedad no es una metáfora” y califica de “siniestras” las metáforas empleadas para concebir y comunicar la enfermedad (Sontag 1980: 9). 
de esta idea metafórica se emplearon conceptos procedentes de la guerra ${ }^{12}$ para conceptualizar y describir una enfermedad, la nueva pandemia. En la narración de esta gripe se activaron los siguientes componentes de un conflicto armado ${ }^{13}$ : el enemigo, que causó daños y víctimas, y al que un ejército le hizo frente mediante el empleo de determinadas tácticas y el uso de cierto armamento. El uso de esta metáfora bélica mostró, como en otras muchas ocasiones, su carácter persuasivo en la construcción de un sentimiento de miedo que impulsaba a los ciudadanos a actuar de una determinada manera con el fin de protegerse.

Ante la aparición de un enemigo inesperado -“Un nuevo enemigo llamado H1N1” (La Vanguardia, 26 de abril)-, estalló la guerra de la gripe A, que puso en alerta a la humanidad, en bloque. La prensa, en la crisis de la gripe A, presentó esta enfermedad como "Una amenaza sin fronteras" (ABC, 27 de abril ${ }^{14}$ ), que convertía en vulnerables a todos los habitantes del planeta. La puesta en escena parecía propia de una

\footnotetext{
${ }^{12}$ Las noticias sobre la gripe $A$, además de equiparar esta enfermedad con una guerra real, hicieron uso de otros recursos interesantes. Por ejemplo, el prefijo anti- se antepuso a palabras relacionadas con las armas empleadas para combatir la gripe A: por una parte, las defensas naturales de cada persona -los anticuerpos-, y, por otra, los antídotos artificiales, entre los que destacan los antivirales, los antirretrovirales como el Antiflu y otros remedios para evitar la expansión del virus como los antigripales y el gel antibacterial. La preposición contra y el prefijo contra- estuvieron también muy presentes en las noticias (contra la gripe A, contrarrestar el virus...). La prensa utilizó, además, eufemismos. Siguiendo la división realizada por Moya (2001), en el tratamiento informativo de la gripe A predominó el grupo constituido por sintagmas compuestos por sustantivo más adjetivo, como fuego amigo, daños colaterales, efectos colaterales y ofensiva vírica. También hubo casos de eufemismos formados por adjetivo precedido por la preposición de y seguido de sustantivo (de baja intensidad) y otros, por una palabra simple (bajas).

${ }^{13}$ En las guerras sanitarias no se plantea una perspectiva de lucha individual sino de combate general, como afirma Vicente Sanchis-Bayarri en su tesis doctoral (2008: 59): "La Sanidad Pública describe la enfermedad como una invasora de la sociedad. En una época era el médico quien libraba la guerra contra la enfermedad. Ahora es la sociedad entera. Se plantean campañas y luchas sanitarias cuyo objetivo es la derrota de un 'enemigo'”.

${ }^{14}$ Puesto que el corpus principal de periódicos analizados en el presente trabajo corresponde al año 2009, solamente se indicará expresamente el año cuando sea otro distinto, caso por ejemplo de informaciones posteriores.
} 
película de ciencia ficción: "Mascarillas, escafandras, gafas, trajes blancos, guantes; figuras que parecen sacadas de una guerra biológica -ésta es también una guerra contra un virus-, infunden un temor irracional en la ciudadanía” (El País, 9 de mayo). Las informaciones abocaban a la necesidad de “Combatir la nueva gripe” (El País, 5 de julio) y, en nuestro país, los cambios en los sistemas de medición llevaron a pensar a muchos “que la pandemia había tomado España al asalto” (El Mundo, 14 de agosto).

La gripe A causó numerosos daños materiales, bajas -quienes no pudieron hacer frente a la enfermedad y murieron- y heridos de guerra -los infectados por el virus y los sospechosos de estarlo o ser portadores del virus. Los muertos, finalmente no fueron tantos como los que se temió en un principio, pero los hubo: “Mevet Inocense, la mujer nigeriana de 33 años a la que derrotó el virus A en apenas siete días, sin presentar factores de riesgo ni una enfermedad latente, viajó semanas atrás desde Madrid hasta Mallorca” (El País, 18 de julio).

Los heridos de guerra -contagiados por la gripe A o sospechosos de estarlofueron víctimas de una fuerte marginación social y xenofobia, a veces por el simple hecho de haber estado en uno de los focos de infección: ““¡Fuera de aquí! ¡Que se los lleven!” Una multitud ataca a los enfermos en Argentina.” (El País, 23 de mayo). El miedo a contraer la enfermedad erigió barreras alrededor de quienes padecían esta gripe o tenían síntomas, como toser o estornudar: "España aislará a los viajeros de México con síntomas” (ABC, 26 de abril).

Algunos fueron tratados como prisioneros de guerra y fueron recluidos, bien en los hoteles, bien en sus casas o bien en hospitales. Los medios de comunicación nos hablaban de ellos: "Los españoles retenidos por la gripe en un hotel de Hong Kong relatan su encierro" (ABC, 4 de mayo); "Nico [...] estos días su casa se asemeja a un búnker: prohibido el aire acondicionado, las ventanas abiertas y salir de su cuarto sin mascarillas (El Mundo, 3 de mayo); [En Massachussets, EEUU] “La nueva legislación contempla el arresto forzoso y sin orden judicial de cualquier sospechoso de haber contraído el virus, la vacunación obligada si las autoridades lo consideran necesario y, si ésta se rechaza, la cuarentena obligatoria” (El País, 28 de septiembre). 
Aparte de los daños personales, la gripe A ocasionó daños materiales en diferentes sectores económicos. Las primeras denominaciones de la gripe A, que hacían referencia al origen animal del virus - gripe porcina- y a la ubicación geográfica de los afectados -gripe mexicana o californiana- tuvieron efectos muy negativos sobre los sectores económicos relacionados con la producción y comercialización de carne de cerdo y el turismo. Así quedó reflejado en la prensa: “Guerra sin cuartel a la carne de cerdo” (El Mundo, 1 de mayo); “España, por su parte, sigue su batalla para que se levante el veto a los productos porcinos en Rusia” (El País, 7 de mayo); "El alcalde de Ciudad de México [...] ha enviado cartas a Bill Gates, Bill Clinton, Bono y Shakira, entre otros para instarles a apoyar a México con testimonios escritos o visitas al país y así reactivar el turismo, un sector duramente golpeado por la epidemia de la gripe A (H1N1” (ABC, 20 de mayo).

El impacto negativo de la gripe A se advirtió en otros ámbitos, como el de diplomacia -“El virus H1N1 tiene una nueva víctima: las relaciones internacionales” (El País 5 de mayo)- y el del deporte: "La gripe A amenaza el debut del Estudiantes" (As.com, 11 de octubre). Sin olvidar las arcas públicas que gastaron millones de euros en la compra de excesivas dosis de vacunas en momentos de crisis económica.

El ejército en esta contienda estuvo encabezado por las autoridades sanitarias en sus diferentes niveles de administración- que actuaron como comandantes de las fuerzas armadas que se preparaban -y preparaban a la población mundial- a hacer frente al enemigo. Lo hacían dirigiendo una amplia tropa, que al principio tuvo como soldados a los profesionales que se ataviaron con mascarillas y trajes que aseguraban su protección, a los que luego se fueron sumando otros colectivos. Sus comparecencias continuas, sus relatos de la situación para informar de lo que ocurría y de los contagios y las pérdidas ocasionadas parecían partes de guerra ${ }^{15}$.

\footnotetext{
${ }^{15}$ En esta crisis hubo también quienes en una guerra real habrían sido considerados como amotinados o rebeldes, que fueron quienes mantuvieron una posición crítica respecto a la actuación y las recomendaciones y órdenes de las autoridades sanitarias. La información de estos rebeldes circuló especialmente a través de los blogs, donde se reflejaron opiniones divergentes de las versiones oficiales sobre la gripe A. Muchos combinaron este cauce con el que ofrece la prensa tradicional para lanzar su interpretación. Fue el caso, por ejemplo, de Teresa Forcades, Pedro Caba y Miguel Jara. La acusación de
} 
La autoridad sanitaria internacional era la Organización Mundial de la Salud (OMS): “La OMS vigila de cerca los contagios por H1N1 fuera de América” (El País, 12 de mayo). Los gobiernos y autoridades sanitarias de cada país, como responsables de la defensa de la salud de los ciudadanos, se sintieron en la obligación de actuar y de dejar bien claro que actuaban. Por eso, adoptaron medidas de protección, informando del modo de hacerlo y colocando en el mercado los medicamentos para evitar contraer la gripe $A$ o, en el caso de haberla contraído ya, ponerle remedio.

En nuestro país, el presidente del Gobierno desempeñó el papel de comandante en jefe, dirigiéndose a los ciudadanos y tratando de reconfortarlos: "Zapatero ha querido enviar 'un mensaje de tranquilidad' a la población ante el avance de una enfermedad que ha dejado dos víctimas mortales en dos meses” (El País, 28 de agosto). Hubo otros cargos públicos que informaban a la población sobre la evolución de la enfermedad: “Sin novedad en España. El consejero de Salud y Bienestar Social, Fernando Lamata, aseguró ayer que aunque no hay novedad sobre la gripe $\mathrm{A}$, los sistemas sanitarios continúan en vigilancia por si hubiera alguna modificación del virus” (ABC, 19 de mayo).

Los colectivos profesionales relacionados con la sanidad fueron reclutados para reforzar la protección de la salud de los ciudadanos: "El Centro Militar de Farmacia está pensando en hacer frente a un ataque bacteriológico” (ABC, 28 de abril); “[en Estados Unidos] cada Estado está reclutando desde pediatras a dentistas, pasando por voluntarios religiosos que puedan administrar la vacuna entre la población” (El País, 28 de septiembre).

Pedro Caba, ex vicepresidente de la Organización Mundial de la Salud (OMS), no pudo ser más directa: “Nos han tomado el pelo, empezando por la OMS y los laboratorios [...]. La fórmula es sencilla: crea el problema, infunde todo el temor posible y luego vende la solución. No falla” (El Mundo, 24 de enero de 2010). 
La Red de Médicos Centinelas, en nuestro país, se consideró también fundamental ante la nueva enfermedad. Así se explicaba su misión en la página web del Ministerio de Sanidad ${ }^{16}$ :

\begin{abstract}
Es una red de médicos de vigilancia de la infección por el virus de la gripe A H1N1, distribuidos por todo el territorio nacional en centros de Atención Primaria y hospitales. Estos médicos confirman mediante pruebas de laboratorio los casos de gripe A H1N1 a una muestra representativa de la población que padece los síntomas de la enfermedad.
\end{abstract}

En la lucha contra la gripe A también intervinieron personajes de televisión de programas infantiles: "La cara más dulce de la lucha contra la gripe A la ha puesto Elmo, el personaje de Barrio Sésamo reclutado por el Gobierno para enseñarle a los niños algunas reglas básicas con las que evitar la propagación del virus” (El País, 28 de septiembre); “Los Lunnis se suman a la lucha contra el virus” (ABC, 3 de octubre).

En cuanto a las tácticas, las autoridades sanitarias adoptaron medidas de protección, informando del modo de hacerlo y colocando en el mercado los medicamentos, el armamento, para evitar contraer la gripe A o, en el caso de haberla contraído ya, ponerle remedio.

Los medios de comunicación reflejaron el avance de la enfermedad y los daños que iba ocasionando a su paso, en función de los que el mando sanitario puso en marcha sus estrategias bélicas y preparó sus armas. Dos cosas parecían claras desde el principio: se trataba de “Una batalla común” (El País, 27 de agosto) y había llegado la "Hora de armarse contra la pandemia” (El País, 29 de abril de 2009).

A finales de abril de 2009, ante la llegada de un virus desconocido se empezaron a diseñar y a poner en marcha tácticas de guerra: “A partir de ahora, Estados Unidos piensa aplicar medidas de ‘vigilancia pasiva’ sobre los viajeros que entran a su territorio procedentes de México (ABC, 27 de abril). Había que vigilar la evolución del agente patógeno: “Tras declarar una emergencia de salud pública para evitar una serie de

\footnotetext{
16 http.//www.msc.es/servCiudadanos/alertas/informesGripeA/090728.htm [Fecha de consulta: 12 de octubre de 2009].
} 
recursos públicos, el presidente Obama ha indicado ayer que la actual ofensiva vírica 'es obviamente una causa de preocupación y requiere un incrementado estado de alerta'” (ABC, 28 de abril). Y es que, según Margaret Chan, directora general de la OMS: “Toda la humanidad está en peligro [...]. Los países deben pasar de la preparación a la acción y preparar de forma inmediata sus planes de emergencia. No hay tiempo que perder” (ABC, 30 de abril).

Las tácticas empleadas en esta guerra contra la gripe $A$ fueron varias. En un primer momento, se trató de contener el virus. La vigilancia y el aislamiento hospitalario o domiciliario- de las personas contagiadas fueron fundamentales. Así lo mostraban los medios de comunicación: "la principal tarea de los servicios sanitarios es vigilar” (El Mundo, 27 de abril); “Algunos países latinoamericanos sí han cerrado sus fronteras (terrestres y aéreas) con México, y Ecuador ha adoptado incluso el estado de excepción” (El País, 1 de mayo).

En una segunda etapa se produce un importante avance del H1N1: "El Gobierno británico considera que su expansión es incontenible” (El Mundo, 3 de julio); y, a partir de ese momento, se plantea un cambio de estrategia: "La alarma es tal que se ha pasado de la 'fase de contención' a la 'fase de tratamiento' en el combate contra la gripe. Esto significa que las autoridades ya no pueden controlar la expansión de la epidemia” (El Mundo, 3 de julio). En España a mediados de julio se anuncia la táctica que se va a aplicar: “'Vamos a actuar en varios frentes a la vez para mitigar en lo posible los efectos de la pandemia', asegura la ministra.” (El País, 18-07-09).

Por lo que respecta al armamento, se emplearon como armas defensivas, o escudos protectores, mascarillas y geles desinfectantes. Las medidas de prevención impusieron, además, un aumento de las distancias sociales. En España, el Colegio de Médicos de Madrid puso en circulación un lema: “No beses, no des la mano, di hola”. Ahora bien, el avance de la gripe A llevó finalmente a las autoridades sanitarias a concluir que las armas defensivas debían combinarse con las ofensivas. La prensa reflejó el cambio de táctica: “¿Qué armas tenemos para luchar contra la pandemia? Además de los antivirales, diferentes compañías están elaborando una vacuna contra la nueva gripe” (El Mundo, 1 de julio). 
En cuanto al primer tipo de armamento, los antivirales: "Son un arma estratégica y terapéutica muy eficaz si se administran en las primeras 48 horas desde el contagio”, ha señalado Jiménez (...).” (El País, 22 de julio). Su modo de actuación es el siguiente: "El Tamiflu y otros antivirales funcionan como la primera barrera de contención de la epidemia. Con ellos se gana tiempo hasta que se logra desarrollar una vacuna eficaz para inmunizar a la población, que aún no ha entrado en contacto con la enfermedad.” (ABC, 28 de abril). La importancia de esta munición en el conflicto explica la noticia siguiente: "España tiene una reserva de 10 millones de dosis (tratamientos completos) de antivirales para hacer frente a la pandemia, una por cada cinco habitantes. Además, acaba de adquirir otros tres millones más para aumentar su almacenaje. Estos fármacos (que se comercializan bajo el nombre de Tamiflú o Relenza), para los que hace falta una prescripción hospitalaria, se han demostrado eficaces en casi todos los casos para tratar el H1N1” (El País, 18 de julio). El Tamiflu se convirtió en un arma tan preciada que fue objeto de custodia: “España cuenta con una reserva de unas 15 millones de dosis. El Ejército guarda en algún lugar secreto y seguro de Burgos, medio millón más”17.

Además de los antivirales hubo otra arma estratégica muy deseada: "Y entre los métodos de contención de la pandemia surge uno ansiado: la vacuna” (El Mundo, 18 de julio). Y es que para algunos: "La única arma contra el virus es inmunizar” (El País, 26 de agosto). Por eso, "EEUU emprende una gigantesca campaña para inmunizar a la población. Massachussets concede poderes al gobernador para combatir la pandemia” (El País, 28 de septiembre) y en España se anuncia: “Contra la gripe A. Llegan las vacunas” (ABC, 8 de octubre).

Finalmente, la guerra se desvaneció sin cumplir los terribles pronósticos. Se preveían consecuencias devastadoras. Sin embargo, un año después del brote de la gripe $A$, el balance dejaba al descubierto que el impacto distaba mucho de lo que durante meses se había anunciado. Una información de El Mundo, del 25 de abril de 2010, hacía este recuento: “Al menos, 150 millones de personas morirán, llegó a fijar la OMS.

\footnotetext{
${ }^{17}$ Raúl Senevilla, Esteban M. Postigo, Javier Caballero, Antoni Trilla, Sandra Fernández, Blanca Paz, Alicia Velasco y Carmen Lucas-Torres. "Especial Gripe A. La guía completa para resolver todas tus dudas. 100 respuestas sobre la gripe A”. Magazine n 518. 30 de agosto de 2009.elmundo.es.
} 
Cuatro veces más que por la gripe del 18, la mayor epidemia de la Historia. Pánico puro y duro. Al final, la cifra se quedó en 17.000 fallecidos en los 208 países en donde el virus supuestamente estuvo presente. [...] la infundada alarma nos costó 333 millones de euros en vacunas y antivirales, inútiles, por otra parte, según numerosos epidemiólogos”.

El anuncio oficial del fin de la contienda llegó dieciséis meses más tarde de la aparición del virus H1N1 -en agosto de 2010- cuando ya casi nadie hablaba de la enfermedad que provocaba: "La OMS declara el fin de la pandemia de la nueva gripe" (El País, 11 de agosto de 2010).

Frente a otros conflictos reales, en esta guerra, en la que se movilizó a los ciudadanos para combatir al virus de la gripe $A$, al final, no hubo vencedores ni vencidos. No venció el virus pero tampoco venció la humanidad. Quienes criticaron la gestión de la gripe A señalaron como único ganador a las industrias farmacéuticas que pusieron en el mercado los medicamentos para prevenir o curar esta gripe, que en principio se presentó como aniquiladora y terrible.

\section{Conclusiones}

El tratamiento informativo de la gripe $A$ en la prensa española, desde su aparición -en abril de 2009- y durante los meses sucesivos se caracterizó por el uso de un discurso bélico, que contribuyó a trazar en la mente de los ciudadanos un paralelismo entre la actuación frente a esta nueva enfermedad y una guerra real.

La metáfora bélica que se empleó para informar sobre el avance de la gripe A no tuvo un mero papel didáctico para facilitar la comprensión de los mensajes y, lejos de ser inofensiva, condujo a una interpretación determinada -terrible- de esta enfermedad que provocó mucho miedo y movió a los ciudadanos a la acción, en busca de armas que les permitieran defenderse y sobrevivir. 
Como en toda guerra, había un enemigo claro que vencer -el virus H1N1, causante de la gripe A- y, frente a él luchaba la humanidad. Primero se percibió la amenaza y, después, llegó el estallido, con muertos y también otras víctimas: los enfermos o sospechosos de estarlo, que fueron aislados y marginados. Hubo daños colaterales y materiales: pérdidas económicas derivadas de la alarma que se suscitó. Las autoridades sanitarias ante esta situación se erigieron en jefes de las fuerzas armadas capitaneando el ejército, en el que se reclutó a profesionales de la sanidad y personajes populares. A ellas les tocó aplicar las tácticas de guerra y el armamento oportuno en cada momento. En esta contienda solo falló el fin del relato, porque no hubo vencedor. El virus resultó muchísimo menos nocivo de lo esperado -causando menos muertes que una gripe estacional-, pero hubo muertos, enfermos, marginados y cuantiosas pérdidas económicas. En medio de la batalla, las voces críticas quisieron resaltar los beneficios de las industrias farmacéuticas, a las que acusaron abiertamente de haber creado el problema para ofrecer ellas mismas la solución.

Al final, la guerra se desvaneció. Poco a poco se dejó de hablar de ella. No hubo victoria ni derrota. Dieciséis meses más tarde de la aparición de la gripe A, la OMS comunicó, a través de un discreto comunicado, el fin del combate, de una crisis sanitaria en cuyo desarrollo adquirió un gran protagonismo un arma persuasiva muy eficaz, la metáfora bélica.

Bibliografía

Álvarez-Dardet Díaz, C. y Davo M.C. (2003). “El genoma y sus metáforas: ¿¿Detectives, héroes o profetas?”. Gaceta sanitaria. Vol 17. N 1. pp. 59-65.

Buckingam, D. (2005). Educación en medios. Barcelona. Paidós.

Camacho, I. (2009). “La 'gripe A' en la prensa española”. Revista Latina de Comunicación Social, 64. pp. 827-843. La Laguna (Tenerife). Universidad de La 
Laguna.http://www.revistalatinacs.org/09/art/865_Bilbao/66_92_Idoia_Camach o.html

Cebrián, S. (2002-2003). “Papel de la metáfora en el discurso ordinario”. Jornades de la Investigació, Universitat Jaume I. www.uji.es/bin/publ/edicions/jf18/hum/2.pdf

Cuenca, M. J. y Hilferty, J. (1999). Introducción a la lingüística cognitiva. Barcelona. Ariel.

Cuenca, M. J. (2009). “The War of the Languages: Metaphors of Linguistic Conflict in Catalonia”. The Annual Joan Gili Memorial Lecture. The Anglo-Catalan Society. University of Birmingham.

Cuenca, M. J. (2010). “Metàfores de conflicte lingüístic: la “Guerra” del català i el castellà a Catalunya”. Quaderns de Filologia. Estudis lingüístics. Vol. XIV (200). pp. 77-96.

Díaz, J. A. (2005). “Terminología médica, cultura e ideología”, Las lenguas de especialidad: nuevas perspectivas de investigación, Quaderns de Filologia. Estudis Lingüístics.Vol. X. pp. 31-51.

Jara, M. (2007). Traficantes de salud. Barcelona. Icaria. 4ª edición 2009.

Jara, M. (2009). La salud que viene. Nuevas enfermedades y el marketing del miedo. Barcelona. Península.

Jara, M. Blog. (www.migueljara.com)

Lakoff, G. \& Johnson (1980). Metaphors We Live By. Chicago. University of Chicago Press. [Trad. Cast.: Metáforas de la vida cotidiana. Madrid. Cátedra. 1986]

Lakoff, G. (1992). «Metaphor and War: the metaphor system used to justify the war in the Gulf». Pütz, M. (ed.): Thirty Years of Linguistic Evolution. Amsterdam: John Benjamins Publishing Company. pp. 463-481.

Lorente, J.I. (2010). “H1N1. Virus, discurso del riesgo y gestión mediática de la alarma sanitaria”. Universidad de La Laguna. Universidad del País Vasco (UPV-EHU).

Morant, R. y Martín, A. (2010). "El lenguaje afectivo durante la crisis sanitaria de la gripe A”. Revista de Dialectología y Tradiciones Populares. Vol. LXV. № 2. pp. 117-134. Julio- diciembre. 
Morant, R. y Martín, A. (2010). "Innovaciones lingüísticas durante la crisis sanitaria de la gripe A: la redenominación y la resignificación”. Español Actual. En prensa.

Moreno, M. Á. (2005). La metáfora conceptual y el lenguaje político periodístico. Tesis Doctoral. Universidad de la Rioja.

Moya, G. (2001). “El lenguaje militar. Tabú, eufemismo y disfemismo”. Tonos Digital. $\mathrm{N}^{\mathrm{o}} 1$.

Muiño, L. (2007). Perder el miedo al miedo. Madrid. Espasa Calpe.

Pastor, Ll. (2008). Parla'm i seré feliç. Badalona. Ara Llibres.

Pastor, Ll. (2010). Si un lleó entrés en un grans magatzems. Badalona. Ara Llibres.

Revuelta, G. y De Samir, V. (2009). Medicina y salud en la prensa diaria. Informe Quiral 10 años. Barcelona. Observatorio de la Comunicación Científica UPF.

Ruiz, L. (2006). “Metáfora y metonimia”. E-Excellence. 15 pp.

Sanchis Bayarri, Vicente (2008): Contribución al estudio de la globalización, la prevención y la cronificación del Sida en la prensa escrita durante el año 2006 en los periódicos El País, El Mundo y el ABC en la prensa científica. Tesis Doctoral. Valencia. Universitat de València.

Sontag, S. (1980). La enfermedad y sus metáforas. Barcelona. Muchnik Editores.

Sontag, S. (1989). El sida y sus metáforas. Barcelona. Muchnik Editores.

Teruel, M. E. (1997). Retòrica, informació i metàfora. Anàlisi aplicada als mitjans de comunicació de massa. Bellaterra / Castelló de la Plana / València. Universitat Autònoma de Barcelona / Servei de Publicacions de la Universitat Jaume I / Universitat de València. Servei de Publicacions.

Tuson, J. (2008). Això és (i no és) Allò. Badalona. Ara Llibres.

Artículos periodísticos

Belmar, I. (2008). “El sucio secreto del marketing”. 24 de abril. www.data-red.com/cgibin/articulos/ver.pl?id=2010911181451

De Benito, E. (2010). “Sin noticias del virus de la nueva gripe”. El País. 9 de agosto, 1. 
De Benito, E. (2010). “La OMS declara el fin de la pandemia de la nueva gripe”. El País. Vida \& artes. 11 de agosto, 26.

Efe (2009). “Los médicos proponen menos besos y más saludos a la japonesa”. 8 de agosto.

Forcades i Vila, T. (2009). “Una reflexión y una propuesta en relación a la nueva gripe”, 16 de septiembre.

www.benedictnescat.com/Montserrat/htmlfotos/TereGipAcas.html

López Arnal, S. (2009). “El marketing del miedo”. 20-11-2009.

www.radio19abril.com/default.aspx?Record=1923\&subCat=7

Mayo, S. (2010). “La buena salud del niño de la 'gripe A' que desató el caos”. El Mundo. Crónica. 25 de abril, 4.

Mediavilla, M. (2009). “Gripes con apellido”, 3 de mayo.

www.larioja.com/20090503/sociedad/guerra-nombres-zanja-inocuo20090503.html.

Rego, P. (2010): El camelo de la gripe A. El Mundo. Crónica. 24 de enero, www.elmundo.es/suplementos/cronica/2010/745/1264287607.html.

Rego, P. (2010): 150 millones de muertos. El Mundo. Crónica. 25 de abril, 5.

Sahuqillo, M. R. (2009). “Los besos ganarán a la gripe A”. El País. Vida \& Artes. 31 de agosto.

http:www.elpais.com/articulo/sociedad/besos/ganaran/gripe/elpepisoc/20090831 / elpepisoc_1/Tes [Fecha de consulta 13 de octubre de 2009]

Senevilla, R. / Postigo, E. M. / Caballero, J. / Trilla, A. / Fernández, S. / Paz, B. / Velasco, A. / Lucas-Torres, C. (2009). Especial Gripe A. La guía completa para resolver todas tus dudas. 100 respuestas sobre la gripe A. Magazine. $\mathrm{N}^{\circ} 518.30$ de agosto. www.elmundo.es

Recibido: 10 diciembre 2010

Aceptado: 3 junio 2011/ Revisado: 18 junio 2011 Publicado: 23 junio 2011/ Actualizado: 25 junio 2011 